Sport, Education and Society

ISSN: 1357-3322 (Print) 1470-1243 (Online) Journal homepage: http://www.tandfonline.com/loi/cses20

\title{
Autonomy, eating disorders and elite gymnastics: ethical and conceptual issues
}

\section{Andrew Bloodworth, Mike McNamee \& Jacinta Tan}

To cite this article: Andrew Bloodworth, Mike McNamee \& Jacinta Tan (2015): Autonomy, eating disorders and elite gymnastics: ethical and conceptual issues, Sport, Education and Society, DOI: $10.1080 / 13573322.2015 .1107829$

To link to this article: http://dx.doi.org/10.1080/13573322.2015.1107829

(c) 2015 The Author(s). Published by Taylor \& Francis.

曲 Published online: 05 Nov 2015.

Submit your article to this journal $₫$

山ll Article views: 515

View related articles $\square$

View Crossmark data $₫$

Full Terms \& Conditions of access and use can be found at http://www.tandfonline.com/action/journallnformation?journalCode=cses20 


\title{
Autonomy, eating disorders and elite gymnastics: ethical and conceptual issues
}

\author{
Andrew Bloodworth ${ }^{\mathrm{a}}$, Mike McNamee ${ }^{\mathrm{b}}$ and Jacinta $\operatorname{Tan}^{\mathrm{c}}$ \\ ${ }^{a}$ College of Human and Health Sciences, Swansea University, Wales, UK; ${ }^{b}$ College of Engineering, Swansea University, \\ Wales, UK; ' College of Medicine, Swansea University, Wales, UK
}

\begin{abstract}
Participation in elite sport, and in particular those sports with special demands in terms of weight and shape, is associated with a higher risk for eating disorders such as anorexia nervosa [Sundgot-Borgen, J., \& Torstveit, M. K. (2010). Aspects of disordered eating continuum in elite high intensity sports. Scandinavian Journal of Medicine and Science in Sports, 20, 112-121]. We report upon research exploring eating attitudes and behaviours within elite gymnastics. The study comprised 42 semi-structured interviews with gymnasts and support staff-34 gymnasts and 9 staff/support staff. The majority of those interviewed were acrobatic gymnasts (22; 16 males and 6 females) with 7 rhythmic gymnasts (all female) and 5 tumblers (all female). The mean age of those gymnasts interviewed was 17.4. A difficulty in precisely delineating extreme eating patterns (disordered eating) from having an eating disorder was noted. Within an elite sports context behaviours thought to be pathological in a more general setting might be fairly commonplace and even functional to the athlete's performance. The extent to which the athlete consents to these patterns of behaviour is problematic given their age and development. We argue that conceptualising consent as 'authority to be cared for by a trustworthy coach', more felicitously applies to the child/adolescent elite sporting context, helping us understand not only the focus of the elite gymnast, but also their relationship with the coach and the coaches' responsibilities.
\end{abstract}

\section{ARTICLE HISTORY}

Received 27 March 2015

Accepted 11 October 2015

KEYWORDS

Autonomy; eating disorders;

gymnastics; sport

\section{Introduction: eating disorders and anorexia athletica}

Research in the domain of eating disorders and sports utilises a number of perspectives. Scientists working within a biomedical paradigm have tended to focus upon prevalence and risk factors (Bratland-Sanda \& Sundgot-Borgen, 2013; Sundgot-Borgen \& Torstveit, 2010) while social scientific approaches have sought to explore the experience of having an eating disorder in a sporting and exercise context (Papathomas \& Lavallee, 2014). There is, however, general agreement across the knowledge domains that participation in elite sport, and in particular those sports with special demands in terms of weight and shape, for example, running and gymnastics, is associated with a higher risk for eating disorders such as anorexia nervosa (Sundgot-Borgen \& Torstveit, 2010).

Eating disorders are characterised by a fear of fatness and drive towards thinness. They cover a spectrum of behaviours and beliefs but are generally characterised by behaviours such as over-exercising, vomiting and laxative abuse intended to aid weight loss; excessive concern, restriction or control over food intake; and body image distortion (American Psychiatric Association [APA], 2013; World Health Organisation, 1994). The Diagnostic and statistical manual of mental disorders (DSM V; APA, 2013) describes

CONTACT Andrew Bloodworth @a.j.bloodworth@swansea.ac.uk

(c) 2015 The Author(s). Published by Taylor \& Francis.

This is an Open Access article distributed under the terms of the Creative Commons Attribution License (http://creativecommons.org/licenses/by/4.0/), which permits unrestricted use, distribution, and reproduction in any medium, provided the original work is properly cited. 
three core feature of anorexia nervosa. The first concerns restriction upon the food that one takes in. The second, rather broad criterion, is either an 'intense fear' of fat, or of gaining weight, or 'persistent behaviour that interferes with weight gain' (APA, 2013). This second criterion allows diagnosis of an eating disorder even if the individual does not explicitly endorse a fear of fat, or offers an alternative reason (perhaps revolving around ideas of control or purity) justifying their persistent attempts to lose weight and prevent weight gain (Brown, Holland, \& Keel, 2014). Finally the DSM V refers to a disturbance in the way in which the individual perceives their weight and shape.

Rather than placing into categories those who do and do not have eating disorders, Sundgot-Borgen and Torstveit (2010) have helpfully discussed the utility of considering an eating disordered continuum in elite sport. This is consistent with eating disorders in the general population, where there is a spectrum of disordered eating, with shifts between different diagnostic categories occurring within individuals (Milos, Spindler, Schnyder, \& Fairburn, 2005). Most sufferers have variants of the three main disorders (anorexia nervosa, bulimia nervosa and binge eating disorder) and are often classified as 'atypical' or 'eating disorder not otherwise specified'. An even larger number of sufferers have sub-clinical eating disorders (Stice, Marti, Shaw, \& Jaconis, 2009). This difficulty of fitting patients into clear diagnostic categories has led the APA (2013) to loosen the criteria in order to include more individuals into the formal diagnostic categories.

The rise of eating disorders within sports has led to the coining of the labels 'anorexia athletica' (Giordano, 2010; Sundgot-Borgen, 1993) and the 'female athlete triad'. Though not a diagnostic classification, the term 'anorexia athletica' is used generally to refer to athletes to whom some of the diagnostic criteria apply without their reaching the thresholds required for full-blown diagnosis. It is also used more loosely to describe athletes exhibiting a pattern of behaviours associated with exercise and eating disorders (Giordano, 2010). The 'female athlete triad', a more clearly operationalised term, is defined as disordered eating, osteoporosis and menstrual abnormalities (Birch, 2005; International Olympic Committee Medical Commission Working Group Women in Sport, 2005, 2008). It is not sufficiently clear how the 'female athlete triad' relates to the formal diagnostic categories of eating disorders. Distinguishing between athletes who have an eating disorder and those who display disordered eating behaviour patterns is a problem of considerable conceptual and clinical complexity.

\section{On the autonomy of the elite gymnast and its application to eating disorders}

Our focus in this essay is precisely how to understand the autonomy of the elite gymnast participants of the study. Autonomy, roughly understood as self-ruling (Buss, 2014), is a difficult notion to comprehend within elite sports contexts. The influence of eating disorders themselves on the capacity of an individual to make their own informed decisions has been the subject of some debate (see Tan, Stewart, Fitzpatrick, \& Hope, 2006). Eating disorders such as anorexia nervosa seem to have limited effect (Tan et al., 2006) on traditional notions of capacity to make informed decisions, understood as the ability to understand, appreciate, reason and to express a choice. This has led to suggestions that it is the notion of 'capacity' itself that needs revising, to account for the manner in which an eating disorder might compromise competence, or the ability to make informed decisions (see Tan et al., 2006). Moreover, it has been suggested that certain values held by the individual might be attributable to pathology, as opposed to being an authentic value that the individual holds (Tan et al., 2006). This of course, begs the question as to how we might distinguish between the authentically held values of the individual, and those associated with the disorder, and even if such a distinction can be sustained (see Hope, Tan, Stewart, \& Fitzpatrick, 2011; Tan et al., 2006). Away from the discussion of eating disorders themselves, the issue of the authenticity of values also concerns how young athletes experience the pressures of elite sport, and how they negotiate these pressures.

\section{Methods}

The research reported upon here entailed semi-structured interviews with gymnasts from the disciplines of acrobatics, tumbling and rhythmic gymnastics, along with support staff. The research project took place from 2011-2013. 
The semi-structured interview format involved two researchers asking the gymnasts a range of open-ended questions. Interviews were transcribed and then analysed for emergent themes. Interviews included questions about the career of the elite gymnast; the pressures associated with being an elite gymnast; the gymnast's approach to weight gain and loss; weighing practices; attitudes towards eating and the gymnast's perceptions regarding body shape and image. In terms of the separate semi-structured interviews with coaches and support staff, these interviews again had a broad remit. Issues addressed related to the broader ethos of elite gymnastics and participants' perceptions of the pressures involved. Such interviews were intended to shed light on how coaches understand and seek to manage the pressures on elite gymnasts, particularly with regard to their weight and shape and how these factors affected the gymnasts' self-perception. Participants in all interviews were assured that their responses would be anonymised. There are, however, limits to this guarantee of anonymity (Tan, Bloodworth, McNamee, \& Hewitt, 2014). These are discussed in greater depth in the research ethics section below.

A total of 42 interviews with 34 gymnasts and 9 staff/support staff ( 1 interview included 2 coaches/ support staff) were conducted. Eighteen female gymnasts and 16 male gymnasts were interviewed. The majority of those interviewed were acrobatic gymnasts (22; 16 males and 6 females) with 7 rhythmic gymnasts (all female) and 5 tumblers (all female) also interviewed. The mean age of those gymnasts interviewed was 17.4. One gymnast did not declare their age. Ages ranged between 12 and 21 . Virtually all gymnasts interviewed reported their highest level of competition as 'international' —with just two reporting their highest level as 'national competition'.

Interviews were transcribed and then analysed thematically with the use of qualitative data analysis package QSR NVivo 9. All researchers were involved in the development of a coding frame, that identified key themes and sub-themes that arose from the interviews. After revisions of the frame, eventually all interviews were coded with use of this tool.

\section{Ethical considerations}

The attitudes of young gymnasts towards their bodies and especially their eating habits are a highly sensitive area of study (see Tan et al., 2014). Thus rigorous procedures were devised by the researchers in order to gain the trust of participants and to protect them. All interviews were conducted by one male and one female researcher. As noted above, the research team included two experienced mental health professionals, who were also experienced researchers in the field of mental health. A mental health professional from the research team was present for all interviews alongside a member of the research team with an in-depth knowledge of sports.

It is commonplace in social scientific research that participants' anonymity will be assured and any data treated confidentially. Care, of course, must be taken with populations whose size or significance might make them more readily identifiable than might be the case with more diffuse populations. Nevertheless, where researchers perceived there to be serious risk to either the participant themselves or another gymnast in the researched environment, it was made clear to participants at the outset that the researchers might need to talk to others to inform them of this. This was particularly important as often we were interviewing young gymnasts under the age of 18 . In those instances where researchers may have thought it necessary to speak to others it was resolved that research participants would be approached prior to any public disclosure.

\section{Results and discussion}

\section{Eating disorders and autonomy}

A preoccupation with weight and shape, and the anxiety, fear or terror associated with gaining weight described by Hope et al. (2011) may serve no positive function and indeed be thought of as pathological outside of a sporting context. But within certain contexts some degree of these 
characteristics might be perceived as functional in terms of aiding sporting performance. It might even be argued that if these attitudes are functional in this sense then they cannot be considered as pathological. In conducting this study we were forced to think very carefully about what constitutes an eating disorder in an elite sport context. It is our contention, however, that a focus on pathology could be too narrow in terms of our understanding the behaviour and attitudes of the athlete and the context within which the athletes train and compete.

One common distinction is to suggest that a disorder is not something chosen by the individual, as a strategy for sporting success for example, but is imposed upon the individual, in a fashion that bypasses their deliberate choice. In terms of a hypothetical gymnast, one would need to consider whether engaging in apparently eating disordered behaviours might be the result of autonomously formed preferences, as opposed to those that are reflective of an eating disorder. While the research was not designed specifically to assess the capacity of the athletes involved, a number of athletes both retired and still competing, demonstrated a high level of critical reflection upon the benefits and disbenefits of their participation in the sport. Here they articulated both the pressures they perceived as an elite gymnast, and how they distinguished between experiencing and dealing with these pressures, and pathology. Thus one female reported on her sporting experiences:

But I've never been to the point where I've been out of control of what I've been eating. But I've always been obsessed with what I've been eating. But I would never say ... I've like starved myself or I've never gone a day without eating but I've always, always been aware of what I've been eating all the time.

Interviewer 2: So it sounds like it was on your mind quite a lot.

Yes it's always on your mind and when I, this time around from the age of like [ ... I I've been a lot more in control of it. I mean I didn't eat a lot at all and what I did eat I constantly knew what I was eating for the right reasons. But I always felt like I was always hungry, like if I felt like I wanted to eat, I knew that I could just eat. Like the minute I finished I just went back into a regular eating plan straightaway. So it never kind of held me back.

There are two key features of this dialogue. First, there is the obsessive attitude towards food that this individual maintained as part of a disciplined, perhaps regimented, approach to achieving sporting success. Second, the gymnast proposes that they have the capability to control or manipulate their disciplined eating practices. If we accept the gymnasts' reflections as accurate, we might distinguish between this behaviour and a pathological concern for controlling food intake. This participant reported a pattern of highly disciplined, obsessive, practices concerning food, weight and shape. Yet they also speak of the ability to 'switch off' such behaviours at will. This control is reported to be within the compass of the gymnast: an expression of their apparent autonomy. Accepted at face value, we may judge that the restrictive actions of the gymnast reflect their authentic desires: I can and must control my intake in order to achieve my sporting goals. Deciding whether the attitudes of the gymnast are autonomously formed, or the result of a mental disorder or pathology affecting the capacity of the gymnast to form their own preferences and attitudes in this domain is exceptionally difficult. The relationship between eating disorders and competence or capacity is a complex one. Tan et al. (2006) report that many patients with diagnosed anorexia nervosa may refuse treatment but not be thought of as lacking capacity, at least as it is currently understood in UK law.

Moreover, bioethicists are not in agreement regarding this issue. Giordano (2010) cites a lack of physiological, genetic or biological evidence to suggest that anorexia nervosa necessarily impairs the individual's capacity. For Giordano the label 'anorexia nervosa' merely describes a set of symptoms. If we accept Giordano's line of argument, efforts to identify pathology (an eating disorder) on the grounds of impaired capacity are doomed to failure. The current conception of capacity at work in UK law, for example, is unable to do this work. There have, however been attempts to challenge this conception of capacity; it is to such attempts that we will now turn.

Hope et al. (2011) have turned to the notion of authenticity in an attempt to explore the implications of living with anorexia nervosa. In particular Hope et al. (2011) consider the demarcation between those values that are the individual's own, and those that are attributable to a disorder 
and are thus inauthentic. The attempt is to distinguish between those values that are coherent with the participant's own goals and those Tan et al. (2006) have elsewhere referred to as pathological values. Pathological values are those that can be attributed to the disorder as opposed to being attributed to the individual's own authentic desires. Tan et al. acknowledge how difficult it might be to identify which values are pathological. One possible route is to consider the individual's previously held values and whether there has been a substantial change in, for example, the devaluation of other aspects of life such as friendship bonds or health status (Tan et al., 2006).

The notion of pathological value however, is not without its problems. Concepts such as 'authenticity' and 'pathological value' have less utility in cases where the individual appears to endorse their apparently disordered desires. An individual may fulfil the medical criteria for an eating disorder but have, what Frankfurt (1971) terms, the will they want to have. This is clearly highlighted in the quotation below:

Because I still don't necessarily see it as a failing. I don't see it as-it's quite an achievement (Laughter). I do genuinely-I would still rather look like that.

And later in the same interview ...

Because I still see it as a bit of a sign of strength. It's a strength of character, not a weakness of character.

Moreover as eating disorders are often accompanied by some ambivalence (Cockell, Geller, \& Linden, 2003; Vitousek, Watson, \& Wilson, 1998) it is not always clear the extent to which an individual concerned endorses their own behaviours, or rejects them, and considers it in some way not their own choice. Added to that, the sporting context provides additional complexity for drawing the line. Many of the traits considered desirable in elite athletes, such as perfectionism and strong compliance, overlap with those found in eating disordered individuals (Thompson \& Sherman, 1999). This overlap in values compounds the difficulty of distinguishing the pathological from the non-pathological. Moreover, literature often discusses sub-clinical variants of eating disorders in an elite sport context (Sundgot-Borgen \& Torstveit, 2010). The proposal here is that while we might not see the full range of symptoms required for a medical diagnosis of an eating disorder, symptoms are still severe enough to use the label 'disordered'.

There are also more fundamental challenges to the overall enterprise of trying to distinguish between the pathological and non-pathological. Rich (2006) is critical of biomedical approaches that see the body as separate, independent parts (Doyal, 1979; Rich, 2006). Being able to trace the origins of a pathological value appeals to the notion that pathology 'within' the individual causes an individual to hold an inauthentic, pathological value. Matthews (2007) is critical of the idea that in the context of mental disorder we ought to search for causes of the disorder, in the same way that we might do when considering physical illnesses. For Matthews understanding mental disorder requires a meaning rather than causal explanation. A causal explanation (perhaps utilising biological or genetic data) might be sufficient for the natural sciences or certain positivist conceptions of the clinical encounter, yet the explanation of human behaviour requires notions of rationality, of which there are no comparators in the natural sciences. Hence in the context of mental disorder and in seeking to identify an eating disorder, we must seek a meaning explanation, ultimately exploring the reasons for certain desires and actions, and suggests Matthews, the intelligibility of such reasons. Such an approach has the further advantage of departing from the individualism that appears to be fostered by a biomedical approach. To consider the reasons offered for a given behaviour is not just to focus on the origin of such reasons in individualistic terms:

the reasons for acting are not, as has been said more than once already, 'in someone's head' or 'in someone's brain', but out there, in the space of ideas that one inhabits with other human beings-part of our being-inthe-world. (Matthews, 2007, p. 116)

This brings us to second problem with focusing on the notion of pathological value. This approach appears indicative of a kind of methodological individualism or essentialism that many sociologists 
and philosophers have been deeply critical of. The focus on pathology within the individual detracts from the importance of the shared notions within a community that shape our understanding of the world (Winch, 1958). In analysing interview transcripts a whole theme developed exploring relations between gymnasts, and between gymnasts and coaches. Many of our gymnasts are effectively engaged in team sports, acrobatic gymnasts that formed part of a pair, or trio for example. These relationships fostered their own pressures. Here we see how the demands of the sport itself, and of teammates' views, foster particular notions of what is appropriate in terms of body weight and shape in order to achieve success. The following helps illustrate how a team or group will develop, along with their coach, shared notions as to what is appropriate in terms of weight and shape, and what is not.

There's not really anyone who's super-the right shape yet, and no one's in their competition shape yet so no one's like getting angry with anyone about their weight really. There's some girls are bigger and need to lose more than others but I think, I think they know that, I'm not really sure we don't really tell-I mean we talk about it, like about the people who need to lose more than others but I think they know.

Interviewer: You talk about it as a group?

Well we don't really tell, we don't tell the person: you need to lose more. But I think the coach does kind of, or the coach hints that - the coach tells everyone and obviously if they put on weight they see that and they're told, but that's obvious to them. Well it should be anyway.

Rich and Evans (2007) discuss the development of body perfection codes in an educational setting. Here we seem to have something similar in which the rules and demands of the sport, along with coaches and other team members aiming for success convey the standards that need to be met in order to achieve such success. That within the sporting environment (club or squad, for example) rules develop that govern behaviour is further illustrated by spontaneous (on the part of the athlete rather than coach initiated) weighing. To reduce the frequency of weighing was a recommendation that resulted from conducting such research. Yet such frequency may have arisen from a development of a shared ethos around what is necessary for success in this sport rather than a consciously exerted pressure to remain a certain weight or shape on the part of a coach for example. One response was to challenge certain unhealthy attitudes towards food, body weight and shape by utilising existing rules and norms, in this instance the drive for success:

And I have talked to her a lot about my experiences, and I've said that, actually-because the only thing I would

say is, although when I personally think I look my best, the results weren't showing as that.

Interviewer: That's interesting.

So although from a -if I was going to show you a photograph of me as a gymnast, l'd want you to perhaps see that one, of when I was at my slimmest. That wouldn't necessarily be when I was at my most successful. And that's the best way I can say those things to other people. You know. It's not going to get you the result that you want, necessarily.

How to understand eating disorders in elite sport contexts is an exceptionally complex problem. Its complexity is heightened by the contested literature depicting the relationship between an eating disorder and the capacity of an individual to autonomously direct their life. To focus only on the issue of pathology, can limit a discussion of this problem. Here we have demonstrated how shared views regarding the body and food can develop in an elite gymnastics environment. In light of such norms we might think disordered responses as both rational and understandable but nevertheless still a cause for concern. In the second section we move to consider how best to understand the autonomy of a young elite gymnast seeking to negotiate the pressures we have discussed.

\section{Autonomy and elite sport}

Raz (1986) proposes certain criteria of for autonomy, or self-rule. These include independence, being free from coercion and manipulation, and the adequacy of options. The latter point refers to having a sufficiently broad range of options from which to choose as one pursues a good life, 
from those short-term trivial (or lesser value) projects to longer term more substantial projects with significant consequences. As Raz points out personal autonomy does not require a particular vantage point from which we once and for all decide what to do with our lives. We make decisions as we go along, and as we gain further information we revise or even reverse previous decisions (Raz, 1986, p. 374). Each time we make decisions we encounter opportunity costs, and this will on occasion close off certain options temporarily or irreversibly. Elite athletes, like many successful persons, may have a narrow focus. This need not, however, entail significantly impaired autonomy. What is important is that the athlete has entered into the participation of sport at this level freely, and is also free to withdraw should they wish:

Interviewer: So what's the differences between you and the other kids at school? You know, it must be a very different life for you compared to them.

Yeah. Because all my friends they normally go out like every night and just hang around the streets.

No, and they always sleep at each other's houses like every night. But I never get to do that. But I don't miss out on everything, because I prefer to do gymnastics competitions.

Interviewer: So it's almost like choosing a different kind of life, isn't it? Yeah.

There is some question, however, as to how best to understand personal autonomy in this context. The quotation below, for example, suggests something a little less straightforward than the athlete entering into a mutually beneficial sporting relationship in which they have fully considered the pros and cons. Here a retired athlete reflects upon the all-consuming nature of elite sport participation. The range of other options available to the athlete has not necessarily been seriously contemplated.

Yes it's affected my life like a whole lot because obviously I went to college but I never went to university because I couldn't do it alongside training. And you've got one goal in your head for so long and then now l've achieved it, when I finished, I kind of felt 'What do I do now?' Almost lost and I felt very, there, maybe two or three months where I felt, I mean it was only last July when I finished. I just felt 'What do I do now, where do I go?'

Because I've never at school, I never thought 'I want to become a doctor, I want to become this, I want to become that'. Never even thought about a career, it's always been gymnastics. Whereas like obviously [ ... ] have always had certain things in their heads... So I'm just like I've never had that and now I've come to the point where I should, I've finished gymnastics now well what do I do?

So obviously coaching is always become, been a natural thing to me so the thing that I see now is me becoming a coach and moving on that way because I feel like I could never leave gymnastics behind because it's been a part of me for so long.

Gymnastic success, more than achievement in most other sports, is what can be called a 'timerelated good' (Slote, 1983), since the powers and capacities involved are built up over many years in line with the maturing body. Regaining high levels of flexibility is exceptionally difficult once lost, and the relative power to weight ratios are exceptionally difficult to achieve. These lead to lower age profiles, though this is somewhat gendered. Male gymnastic manoeuvres are more characterised by strength, which permits a longer maturational period. An issue that is relevant to the freedom to choose one's life course is the fact that gymnasts typically begin body conditioning and learning the skills constitutive of gymnastics and undertaking the very challenging body conditioning required from the age of 6 . Moreover, in terms of socialisation, they are being exposed to role models like older elite gymnasts from whom they will take on habits and norms without their deliberate awareness. By the age of 9-12 they are entering serious training, which then entails considerable sacrifice of other activities and a narrowing of interests. By the time they are themselves considered elite gymnasts, they will have spent their entire adolescence narrowly in pursuit of sporting success and are often identified with the sport as well as exposed to its ethos and values throughout their formative years. Like individuals who have had eating disorders since early adolescence, one can question whether the range of choices is already limited and the values and choices of elite 
gymnasts regarding career choices and the drive to thinness is authentic (Hope et al., 2011; Tan, Hope, \& Stewart, 2003) or whether it mitigates against other potential ethical criteria such as the 'right to an open future' (Dixon, 2007; Feinberg, 1980).

Joan Tronto's feminist theorising in the field of medical ethics might provide us with a concept more apt to understand autonomy in the relationship between coach and athlete, and of participation in early specialising sports. Tronto (2009) offers an interpretation of the relationship between doctor and patient that might help inform our understanding of the coach-young gymnast relationship. Tronto's concern is with the quality of consent in operation. For Tronto, consent-as-autonomy is understood as 'a final outward manifestation of an internal calculus' $(2009$, p. 189). She argues that this is a flawed way of understanding the consent offered in medical settings. Considering consent in this way fails to account for the power differentials between the patient and the doctor. It assumes what the feminist philosopher, Annette Baier (1995), calls the 'contractualist understanding of ethics', which starts by assuming that parties to contracts are equally positioned. Clearly, in our gymnastics' scenario, this assumption is more than problematic. Tronto also notes the difficulty a patient might have in weighing medical information, and the resulting trust that patient places in the health professional.

For Tronto the autonomy expressed in clinical encounters is not that which requires 'a complete agreement with the deal being offered, but a renewal of expression of trust in the care that one has received' (2009, p. 193). What follows from understanding consent as the granting of authority, as Tronto suggests, as opposed to surrendering individualised personal autonomy, is significant. What follows from granting authority to in this case the doctor, is a recognition of the caring and trustworthy relationship between doctor and patient, and unequal power relationship between the two. It also urges us to think of the responsibilities that follow from the granting of such authority to the doctor.

In the context of sports generally, and in particular eating patterns adopted for training and performance in elite gymnastics, the child or adolescent athlete does not appear to operate with a mature and ongoing assessment of the pros and cons of deeply committed participation including risk and benefits with respect to long-term health and welfare. Even in clinical contexts Tronto suggests that such assessments are difficult to make. So the athlete appears to renew their trust in the coach with each season, or by key episodes within any season (mastering a new move, being safely supported while learning a dangerous new move and so on). The trust between athlete and coach is key here, as are the responsibilities that arise from this relationship. As Baier (1995) reminds us, trust grows thick, not thin with use. This notion was reinforced on many occasions, including in the remark that:

I think because when you're little you don't know obviously whether something is dangerous until you do it. So if the coach has told you to do something and you do it and you realise you're safe and you build up that trust with the coach. That the coach wouldn't ask you to do something if it was dangerous and then obviously as you get older you just continue with that. When I was at ... my coach, because of my age, was more liberal and said 'You can choose what you want to do with your training and I'll let you do what you want and I'll just coach you.'

But I much prefer being here and being treated like everyone else and just being told 'You're going to do this, you're going to do that.' I like having that structure to my training because ... I don't really know why ...

The coach is the only person who can tell you whether you can or can't do it. No-one else, regardless of whether your parents say 'You can do it you can't do it' they have absolutely no idea of the actual mechanisms of the work and the preparation that you need and the skills preceding up to performing.

These quotations illustrate the power entrusted in the coach over the athlete in subtle ways (McNamee, 1998a). Central to an understanding of this trust, understood as a moral not an economic concept, is the vulnerability of one of the parties; that is, the child or adolescent, who is in a long-term trusting relationship with the coach in loco parentis. Indeed the long-term coach may be a more powerful advocate for behaviours and choices than parents, since the coaches are seen as the key gatekeeper through which the gymnasts' embodied capital has been developed (McNamee, 1998a, 1998b). The athlete suggests, with reference to technical aspects of the sport, that it is the coach who is best placed to inform the athlete as to whether something is possible, or not, and/or 
when. This offers support for the employment of Tronto's notion of 'consent as authority' in this domain. The athlete does not undertake an internal calculation of risk and reward, but places their trust in the coach and their assessment of the best manner in which to participate in the sport.

This male coach again offers a reflective assessment of the club's attitude towards both athlete welfare and more technical aspects of the discipline.

Erm, I think it's because we tend to be more, have a much more humanistic approach with our gymnasts. We tend to involve them in their training, in discussions about what they do. Obviously they have aspirations, but then we've got to set realistic goals. You can't, there's no point us saying with those gymnasts 'Well you've got to be able to achieve full twist and triple.' Because we know, for the size and weight, it's impossible. So we have to almost negotiate and say 'Well let's see what we can get.'

And I've got to say that [ ... ], they've actually exceeded my expectations. [ ... ]. But that's just been hard work and in probably most of the clubs in this country they would have been finished. It would have said 'Well you're going to get a little bit small top.' They would have stopped them. But that's more, having that relationship with those gymnasts. And the thing is I think a lot of coaches who will have small tops and restrict their diets, it's because it's easier with a small top. It's much easier to teach the skills, it's much easier to achieve that level and you can do it in a shorter time. So they're looking for quick fixes really. Right this year we need this result. Alright you've got too big, right get another one in.

Whereas we've, I mean we've kept these together for, [ ... ] they've been together now. We've changed one of the bases occasionally, but the basic structure, the top and the middle, they've been together. And I think that helps as well, if you can keep a partnership together for a long time.

While the involvement in training discussions of the athlete was not something we found commonplace among all age groups of gymnasts in the study, the process of negotiation was spoken of more frequently by older gymnasts. Here the coach discusses the 'top'-an athlete thrown and caught by other gymnasts-in the discipline of acrobatics-who are situated at the base or middle of a pairing, trio or foursome. A 'top', who tends to be much younger and therefore less experienced than the bases, experiences considerable pressure with regard to weight and/or shape, being thrown and balanced at the top of a formation, which significantly affects the performance of the team.

In the quotation above, the coach cites the closeness of the relationship between coach and gymnast as a means to overcome technical obstacles and prolong the competitive career of the 'top'. The coach is aware of his responsibilities towards the gymnast, and of the relationship fostered, between the team of gymnasts and with the coach. The coach has sought to focus on technique as opposed to diet, and to focus on preserving the career of young gymnasts, rather than focusing on quick (and potentially damaging) fixes. In Tronto's (2009) terms the relationship between coach and athlete has fostered responsibilities that extend beyond the short-term world of elite sport success.

These responsibilities were not only felt by coaches. This pressure was acknowledged by those gymnasts lower in the team (i.e. beneath the 'top'). The dialogue below illustrates the pervasiveness of weight and shape concerns in this environment. It also illustrates how this athlete sought to respond to that, to best protect those younger athletes thought to be vulnerable.

Because I think when you start younger, you're exposed to all the people who are already in the sport and who are already bothered about their weight and who have more knowledge of it and I think when you're working with them it's very hard for you not to pick up on that.

Interviewer: Tell me more about what it 5 actually literally like when you re working with these people?

I think it's not as much of a problem in our gym but from gyms that I've heard about, the tops are encouraged to be as thin as they can because you go higher, and because you go higher you get more marks and stuff like that. So I think they think, like, it's their job, like their part of the trip, their part of whatever they're in to be thin and things like that. And I think they kind of think we want to be like the big girls and be-we want to be as thin as them, we want to watch our weight, we want to-things like that. But I don't think they understand as much because they're so young. 
Interviewer: So it 5 almost like the big girls might have the, you know, oh my bum sticks out', kind of thing and the little ones are trying [crosstalk].

Yes they start picking up on that. Because, like, if we said to [name of younger gymnast], like say 'oh my legs look

fat' she'd like 'do you think mine are'. Which I think is a bad thing for her to be introduced to.

Disciplines such as acrobatic and rhythmic gymnastics which have a team element, foster close knit relationships between team members. This creates additional externalised pressure and responsibility on individuals to maintain their weight, train hard and attain the level of discipline (and uniformity of body shape) required for elite performance. It might also mean that these relationships provide vehicles for the replication of pathological values concerning weight and shape. Here the athlete consciously sought to avoid the transmission of such potentially damaging values, illustrating the responsibility she felt to other younger members of her group.

This section has attempted to reflect critically on what is meant by autonomy; in a sporting context of unequals, between the powerful coach and the less powerful gymnast, and even between more and less powerful gymnasts-both physically and psychologically-operating in a team sport. It is clear that the coach is the gatekeeper to the aspirations of the child or adolescent gymnast into the highly prized status of elite athlete. Tronto's discussion of consent has been utilised to distinguish between 'consent as autonomy' and 'consent as authority'. We have argued that the latter more fruitfully applies to the child/adolescent sporting context, helping us understand not only the focus of the elite gymnast, but also their relationship with the coach, and indeed of the responsibilities that follow from such a conceptualisation.

\section{Conclusion}

This essay aimed to enhance our understanding of eating attitudes, along with attitudes towards weight and shape in the context of elite gymnastics. First, it illustrated the highly disciplined, at times obsessive attitude towards weight and shape evident within certain gymnastics disciplines, and in particular roles within such disciplines. Indicative of this environment where weight and shape concerns are ever present, is the challenge in distinguishing between what might be thought of as pathological attitudes towards food, weight and shape, and those chosen as a perceived means of enhancing sporting success. We encountered as researchers some troubling practices within the elite sporting context. Such practices are unlikely to be restricted to gymnastics (Bachner-Melman, Zohar, Ebstein, Elizur, \& Constantini, 2006; Byrne \& McClean, 2002; Sundgot-Borgen et al., 2013).

There is no clear-cut response to the naïve question regarding which is the 'real' or 'proper' concept of 'autonomy'. Not only is it a deeply contested concept, whose meaning alters significantly according to the context, it is a notion that admits of varying degrees. The precise point at which we might consider apparently unhealthy or self-harming behaviours to be pathological, and sufficient to claim that someone is non-autonomous and perhaps even disordered is notoriously difficult to establish. This problem must be seen in a broader landscape of the conceptual and epistemic difficulties of classification of mental illness and capacity. In choosing to focus on issues of autonomy and eating disorders, we have not addressed these broader issues head-on. They concern, however, the justification of sports policies that concern athlete autonomy, for example, whether to exclude athletes from competition on mental health grounds.

An additional problem in applying the concepts of eating disorders to elite sport or sport in general is the differences in perspective between the medical and sporting paradigms. In medical or mental health settings, eating disorders are viewed as 'mental disorders' and there is an assumption that this often confers impairment of general functioning as well as vulnerability or difficulty making treatment decisions which then justify compulsion. In the sports settings, by contrast, a preoccupation with maintaining rigid control over weight and shape and endocrinological consequences such as abnormalities of menstrual cycles may be endemic, normalised, perceived as highly functional and indeed essential or desirable for success. In our research, although the coaches were all concerned to protect their 
gymnasts from eating disorders, there was little conception of at what point this occupational preoccupation with weight and shape psychologically becomes 'mental disorder'. Prior research on eating disorders has tended to apply medical definitions and questionnaire instruments to sportsmen and women in order to determine the prevalence of eating disorder; but the applicability of population norms regarding weight and body fat and population-derived questionnaires for 'abnormality' of behaviours and attitudes regarding weight and shape is questionable.

Finally, we noted that autonomy extends beyond issues of individualised rational decisionmaking. A more context sensitive understanding of the developing nexus of power relations in the child/adolescent sporting milieu has been advocated. Moreover, this sensitivity must be heightened in the contexts of elite sport where developing autonomy is seen against a background of narrowing interests and identifications. The elite young athlete can be swallowed up by the intensity of the elite sports milieu. Making judgements about whether disordered eating patterns are the object of choice, requires sensitivity to the age of the gymnast; their age at commencement in the sport, and intensification of their commitment to it; the availability of other leisure options; the sources of value of those options in comparison with their self-esteem and positive peer evaluations in virtue to their elite athlete status and so on. A more nuanced comprehension of these factors, alongside an understanding of the extent to which their trust is properly granted to the powerful other (the coach) is also central to our understanding of whether their perfectionism is pathological or not, as revealed in the words of the gymnasts and to a lesser extent by their coaches.

Finally, we have noted the significance of the relationships, between coach and gymnast, and between older and younger gymnasts, in a sport in which gymnasts clearly perceive significant pressures in terms of weight and shape. These close relationships facilitate the 'passing down' of problematic attitudes and practices. These relationships, as we have seen, however, might also reflect the responsibility that senior athletes, both male and female, feel towards young gymnasts, who have placed their trust in coaches and older teammates.

\section{Disclosure statement}

No potential conflict of interest was reported by the authors.

\section{Funding}

We gratefully acknowledge that the research was funded by ESRC, project title: Ethical aspects of the impact of eating disorders on elite gymnasts [grant number RES-000-22-4021].

\section{References}

American Psychiatric Association. (2013). Diagnostic and statistical manual of mental disorders (DSM-V) (5th ed.). Washington, DC: American Psychiatric Publishing, Incorporated.

Bachner-Melman, R., Zohar, A. H., Ebstein, R. P., Elizur, Y., \& Constantini, N. (2006). How anorexic-like are the symptom and personality profiles of aesthetic athletes? Medicine \& Science in Sports \& Exercise, 38(4), 628-636.

Baier, A. (1995). Moral prejudices: Essays on ethics. Cambridge, MA: Harvard University Press.

Birch, K. (2005). Female athlete triad. British Medical Journal, 330(7485), 244-246.

Bratland-Sanda, S., \& Sundgot-Borgen, J. (2013). Eating disorders in athletes: Overview of prevalence, risk factors and recommendations for prevention and treatment. European Journal of Sport Science, 13(5), 499-508.

Brown, T. A., Holland, L. A., \& Keel, P. K. (2014). Comparing operational definitions of DSM-5 anorexia nervosa for research contexts. International Journal of Eating Disorders, 47(1), 76-84.

Buss, S. (2014). Personal autonomy. In Edward N. Zalta (Ed.), The Stanford encyclopedia of philosophy (Spring 2014 Edition) Stanford, CA: Stanford University. Retrieved June, 2015, from http://plato.stanford.edu/archives/spr2014/entries/ personal-autonomy/

Byrne, S., \& McLean, N. (2002). Elite athletes: Effects of the pressure to be thin. Journal of Science and Medicine in Sport, 5 (2), 80-94.

Cockell, S. J., Geller, J., \& Linden, W. (2003). Decisional balance in anorexia nervosa: Capitalizing on ambivalence. European Eating Disorders Review, 11(2), 75-89. 
Dixon, N. (2007). Sport, parental autonomy, and children's right to an open future. Journal of the Philosophy of Sport, 34(2), 147-159.

Doyal, L. (1979). The political economy of health. London: Pluto Press.

Feinberg, J. (1980). The child's right to an open future. In W. Aiken \& H. LaFollette (eds.), Whose child? (pp. 124-153). Totowa, NJ: Rowman \& Littlefield.

Frankfurt, H. G. (1971). Freedom of the will and the concept of a person. The Journal of Philosophy, 68(1), 5-20.

Giordano, S. (2010). Exercise and eating disorders: An ethical and legal analysis. Abingdon: Routledge.

Hope, T., Tan, J., Stewart, A., \& Fitzpatrick, R. (2011). Anorexia nervosa and the language of authenticity. Hastings Center Report, 41(6), 19-29.

International Olympic Committee Medical Commission Working Group Women in Sport. (2005). Position stand on the female athlete triad. Retrieved September, 2015, from http://www.olympic.org/documents/reports/en/en_report_917.pdf

International Olympic Committee Medical Commission Working Group Women in Sport. (2008). Position stand on the female athlete triad. Retrieved September, 2015, from http://www.femaleathletetriad.org/ triad/wp-content/ uploads/2008/10/ioc_position_stand_on_female__athlete_triad.pdf

Matthews, E. (2007). Body-subjects and disordered minds: Treating the whole person in psychiatry. Oxford: Oxford University Press.

McNamee, M. (1998a). Contractualism and methodological individualism and communitarianism; situating understandings of moral trust in the context of sport and social theory. Sport, Education and Society, 3(2), 161-179.

McNamee, M. J. (1998b). Celebrating trust: Virtues and rules in the ethical conduct of sports coaches. In M. J. McNamee \& S. J. Parry (Eds.), Ethics and sport (pp. 148-168). London: Routledge.

Milos, G., Spindler, A., Schnyder, U., \& Fairburn, C. G. (2005). Instability of eating disorder diagnoses: Prospective study. The British Journal of Psychiatry, 187(6), 573-578.

Papathomas, A., \& Lavallee, D. (2014). Self-starvation and the performance narrative in competitive sport. Psychology of Sport and Exercise, 15(6), 688-695.

Raz, J. (1986). The morality of freedom. Oxford: Clarendon Press.

Rich, E. (2006). Anorexic dis(connection): Managing anorexia as an illness and an identity. Sociology of Health and Illness, 28(3), 284-305

Rich, E., \& Evans, J. (2007). Re-reading voice: Young women, anorexia and performative education. Junctures: The Journal for Thematic Dialogue, 9, 39-54.

Slote, M. A. (1983). Goods and virtues. Oxford: Oxford University Press.

Stice, E., Marti, N. C., Shaw, H., \& Jaconis, M. (2009). An 8-year longitudinal study of the natural history of threshold, subthreshold, and partial eating disorders from a community sample of adolescents. Journal of Abnormal Psychology, 118 (3), 587-597. doi:10.1037/a0016481

Sundgot-Borgen, J. (1993). Prevalence of eating disorders in elite female athletes. International Journal of Sports Nutrition, 3, 29-40.

Sundgot-Borgen, J., Meyer, N. L., Lohman, T. G., Ackland, T. R., Maughan, R. J., Stewart, A. D., \& Múller, W. (2013). How to minimise the health risks to athletes who compete in weight-sensitive sports review and position statement on behalf of the ad hoc research working group on body composition, health and performance, under the auspices of the IOC medical commission. British Journal of Sports Medicine, 47, 1012-1022.

Sundgot-Borgen, J., \& Torstveit, M. K. (2010). Aspects of disordered eating continuum in elite high intensity sports. Scandinavian Journal of Medicine and Science in Sports, 20, 112-121.

Tan, J., Stewart, A., Fitzpatrick, R., \& Hope, R. A. (2006). Competence to make treatment decisions in anorexia nervosa: Thinking processes and values. Philosophy, Psychiatry and Psychology, 13(4), 267-282.

Tan, J. O., Hope, T., \& Stewart, A. (2003). Anorexia nervosa and personal identity: The accounts of patients and their parents. International Journal of Law and Psychiatry, 26(5), 533-548.

Tan, J. A. O., Bloodworth, A. J., McNamee, M. J., \& Hewitt, J. L. (2014). Investigating eating disorders in elite gymnasts: Conceptual, ethical and methodological issues. European Journal of Sport Science, 14(1), 60-68.

Thompson, R. A., \& Sherman, R. T. (1999). 'Good athlete' traits and characteristics of anorexia nervosa: Are they similar? Eating Disorders, 7, 181-190.

Tronto, J. C. (2009). Consent as a grant of authority: A care ethics reading of informed consent. In H. Lindemann, M. Verkerk, \& M. U. Walker (Eds.), Naturalized bioethics: Toward responsible knowing and practice (pp. 182-198). Cambridge: Cambridge University Press.

Vitousek, K., Watson, S., \& Wilson, G. T. (1998). Enhancing motivation for change in treatment-resistant eating disorders. Clinical Psychology Review, 18(4), 391-420.

Winch, P. (1958). The idea of a social science and its relation to philosophy. London: Routledge \& Kegan Paul.

World Health Organisation. (1994). F50.0: Anorexia nervosa. In ICD-10 classification of mental and behavioural disorders. Geneva: Author. 